\title{
Sensitivity of Warm-Frontal Processes to Cloud-Nucleating Aerosol Concentrations
}

\author{
Adele L. IGEL AND SUSAN C. VAN DEN HEEVER \\ Colorado State University, Fort Collins, Colorado \\ CATHERINE M. NAUD \\ Columbia University, New York, New York \\ STEPHEN M. SALEEBY \\ Colorado State University, Fort Collins, Colorado \\ DEREK J. POSSELT \\ University of Michigan, Ann Arbor, Michigan
}

(Manuscript received 5 June 2012, in final form 24 January 2013)

\begin{abstract}
An extratropical cyclone that crossed the United States on 9-11 April 2009 was successfully simulated at high resolution (3-km horizontal grid spacing) using the Colorado State University Regional Atmospheric Modeling System. The sensitivity of the associated warm front to increasing pollution levels was then explored by conducting the same experiment with three different background profiles of cloud-nucleating aerosol concentration. To the authors' knowledge, no study has examined the indirect effects of aerosols on warm fronts. The budgets of ice, cloud water, and rain in the simulation with the lowest aerosol concentrations were examined. The ice mass was found to be produced in equal amounts through vapor deposition and riming, and the melting of ice produced approximately $75 \%$ of the total rain. Conversion of cloud water to rain accounted for the other $25 \%$. When cloud-nucleating aerosol concentrations were increased, significant changes were seen in the budget terms, but total precipitation remained relatively constant. Vapor deposition onto ice increased, but riming of cloud water decreased such that there was only a small change in the total ice production and hence there was no significant change in melting. These responses can be understood in terms of a buffering effect in which smaller cloud droplets in the mixed-phase region lead to both an enhanced vapor deposition and decreased riming efficiency with increasing aerosol concentrations. Overall, while large changes were seen in the microphysical structure of the frontal cloud, cloud-nucleating aerosols had little impact on the precipitation production of the warm front.
\end{abstract}

\section{Introduction}

Extratropical cyclones are the primary transporters of moisture, heat, and energy poleward in the midlatitudes (e.g., Trenberth and Stepaniak 2003; Schneider et al. 2006). The fronts associated with extratropical cyclones contribute approximately $68 \%$ of the total precipitation at midlatitudes (Catto et al. 2012). Additionally, their deep and extensive cloud shields have large impacts for radiation locally and on climate scales (e.g., Ramanathan

Corresponding author address: Adele Igel, Colorado State University, 1371 Campus Delivery, Fort Collins, CO 80523.

E-mail: adele.igel@colostate.edu et al. 1989; Stewart et al. 1998). Should aerosols be able to alter the radiative, microphysical, and/or dynamical properties of extratropical cyclones, they could have important consequences for global change scenarios. However, very few studies have investigated the indirect effect of aerosols on extratropical cyclones, despite the fact that both changes in pollution emissions globally and local seasonal enhancements of aerosol concentrations because of burning could impact these systems, as shown conceptually by Wang et al. (2009).

Aerosols can affect cloud systems by changing the microphysical structure of clouds. A change in cloud microphysical structure can affect the radiative properties of clouds (Twomey 1977), change the lifetime of

DOI: 10.1175/JAS-D-12-0170.1 
clouds (Albrecht 1989), or alter the rates of microphysical processes associated with precipitation production and latent heat release. Changes in diabatic heating rates can then induce changes in vertical velocities and other dynamical fields. Understanding all of these indirect effects and feedbacks of aerosols is an ongoing and difficult task, especially since the environment and dynamics of the system itself can alter the response to aerosols (Matsui et al. 2006; Fan et al. 2009; Khain 2009; Storer et al. 2010). Since the mesoscale dynamics of an extratropical cyclone differ greatly between the cold and warm fronts, a detailed study of all of the impacts of aerosols on extratropical cyclones is too extensive for one study; therefore, this paper will focus on just one part of the extratropical cyclone, the warm front.

While there are no studies reported in the literature that specifically examine the influence of aerosols on warm fronts, aerosol impacts on other mixed-phase cloud systems have been investigated, and the results of these studies are likely to be relevant to this study. Cheng et al. (2010) examined a mixed-phase front system in Taiwan and found that precipitation could be either increased or decreased with increasing cloud condensation nuclei (CCN) depending on changes in the depositional growth of ice and riming. $\mathrm{CCN}$ in mixedphase clouds have been shown to result in decreased riming efficiency in observations (Borys et al. 2003) and modeling studies of mixed-phase orographic clouds (Saleeby et al. 2009; Xue et al. 2012) because of decreased supercooled cloud droplets sizes. Both observations and modeling studies of these clouds show changes in the spatial distribution of precipitation (e.g., Givati and Rosenfeld 2004; Jirak and Cotton 2006; Lynn et al. 2007; Saleeby et al. 2009) but do not always agree on the magnitude or sign of the total precipitation change, which can depend on environmental factors and the extent of the mixed-phase region (Muhlbauer et al. 2010; Zubler et al. 2011). Many results of mixed-phase convective cloud studies indicate that higher $\mathrm{CCN}$ concentrations can cause more liquid water to be lofted above the freezing level leading to additional freezing and latent heat release (Khain et al. 2005; van den Heever et al. 2006). The enhanced buoyancy and feedbacks to the updraft are often referred to as the aerosol invigoration effect, but this effect has not been studied extensively in nonconvective cloud types.

In addition, should aerosols be able to significantly alter latent heating rates, results of studies that examine the sensitivity of warm fronts to latent heating may also be relevant to this study. First, modeling studies have shown that latent heat processes, including condensation and melting, lead to mesoscale banded features over the warm-frontal surface (Hsie et al. 1984; Szeto and Stewart 1997). Evaporational and sublimational cooling can enhance regions of mesoscale descent (Huang and Emanuel 1991; Clough et al. 2000). Through these modifications of vertical velocity and circulation, as well as through local changes in the thermal structure, latent heating has been seen to accelerate frontogenesis and frontal propagation speed for both warm and cold fronts (Hsie et al. 1984; Szeto and Stewart 1997; Reeves and Lackmann 2004).

Before the impacts of aerosols on warm fronts can be fully understood, the budgets of ice and liquid hydrometeor mass in warm-frontal clouds must be examined since aerosol indirect effects vary with cloud phase. Such budgets of cloud ice and rain, but not cloud water (here and throughout the study, "cloud water" means "cloud liquid water"), have been studied before by Rutledge and Hobbs (1983) and Gedzelman and Arnold (1993) for warm fronts; however, both of those studies used idealized, two-dimensional model setups with more primitive microphysical schemes than is used in the present study. The current work will expand on these previous studies by presenting budgets of ice, rain, and for the first time cloud water for warm-frontal clouds from a three-dimensional, high-resolution cloud-resolving simulation that employs sophisticated microphysics and aerosol parameterization schemes. The sensitivity of the budgets and latent heating profiles of the warm front will then be tested by altering the background profile of cloud-nucleating aerosol concentration in two additional simulations.

In section 2, the model will be described and a synoptic overview of the selected storm given. In section 3, data analysis methods will be described. Section 4 includes the budgets of ice, cloud water, and rain, in warmfrontal clouds. In section 5 the sensitivity of these budgets and the warm front as a whole to perturbations in aerosol concentrations is discussed.

\section{Case overview}

\section{a. Case selection and model setup}

To approach this problem, an extratropical cyclone was simulated using the Regional Atmospheric Modeling System (RAMS) (Pielke et al. 1992; Cotton et al. 2003). The case selected was the extratropical cyclone that developed in the lee of the Rocky Mountains and tracked across the United States from 9 to 11 April 2009. This case was selected for several reasons. Most importantly, it had a long-lived and well-defined warm front. Additionally, no other extratropical cyclone was near enough to interact with this storm, which would further complicate the analysis. Third, the case was chosen because it did not 
move from water to land or vice versa until after the simulation period. In this way transitions between water and land surfaces do not complicate interpretation of the results.

The simulations were set up with an outer and inner two-way nested grid, the locations of which are shown in Fig. 1a. The outer grid has $250 \times 300$ grid points with 15 -km horizontal spacing $(3750 \mathrm{~km} \times 4500 \mathrm{~km})$ while the inner grid has $697 \times 1027$ grid points with 3 -km horizontal spacing $(2091 \mathrm{~km} \times 3081 \mathrm{~km})$. While portions of fronts and extratropical cyclones have been run at finer resolution (e.g., Garvert et al. 2005; Molthan and Colle 2012), to our knowledge, no extratropical cyclone in its entirety has been simulated at such a high grid resolution before. Both grids have 45 vertical sigma levels, with $75-\mathrm{m}$ spacing near the surface stretching to $1-\mathrm{km}$ spacing at the model top. The time steps on the inner and outer grids were 5 and $20 \mathrm{~s}$, respectively. A cumulus parameterization scheme based on Kuo (1974) and Molinari (1985) was implemented on the outer grid only. The Harrington (1997) radiation scheme and a Smagorinsky (1963) turbulence scheme with modifications by Lilly (1962) and Hill (1974) were implemented on both grids.

The simulations use a two-moment bin-emulating microphysical scheme that includes five prognostic ice species: pristine ice, snow, aggregates, graupel, and hail, and three prognostic liquid species: two cloud droplet modes and rain (Meyers et al. 1997; Saleeby and Cotton 2004, 2008). Graupel and hail are distinguished by density rather than size in the RAMS microphysics scheme (Walko et al. 1995). Their densities are defined to be 0.3 and $0.9 \mathrm{~g} \mathrm{~cm}^{-3}$, respectively. These densities for graupel and hail allow for a transition in density as ice particles become more heavily rimed or gradually melt and therefore allow the fall speeds of these particles to be more accurately computed. Graupel and hail both have diameters of approximately 1-2 $\mathrm{mm}$ in these simulations; however, the hail concentration is about 4 times larger than that of graupel and dominates the mixing ratio because of its higher density. While hail is not typically associated with warm fronts, the "hail" produced by the model is more appropriately described as heavily rimed ice or partially melted ice, particularly below the melting level. Both graupel and hail can be, but are not necessarily, partially melted. Therefore, we will refer to them as the "mixedphase" species throughout the remainder of the text.

By using a bin-emulating scheme, each species is binned by size for the calculation of collection efficiencies and fall speeds; these calculations give a more accurate representation of riming and autoconversion than can be simulated by using a traditional bulk microphysics scheme. This parameterization scheme is therefore well suited for the study of the microphysics and precipitation of the warm front without being too memory intensive.

RAMS explicitly tracks the rates of many cloud processes. Those that will be presented here (the names used in the figures are given in parentheses) are total vapor deposition and sublimation of ice species (vapor to ice), total condensation and evaporation of cloud species (vapor to cloud) and rain (vapor to rain), cloud droplet nucleation (cloud nucleation), conversion of cloud water to rain through autoconversion of cloud droplets and accretion of cloud droplets by rain (cloud to rain), melting (melting), riming of cloud droplets (riming of cloud) and raindrops (riming of rain), and collection of ice by rain resulting in the melting of the ice (ice to rain). These allow for the budgets of ice, cloud water, and rain to be explicitly calculated in the simulations. Note though that the two processes comprising each of the following pairs-deposition and sublimation, condensation and evaporation, and the cloud to rain processes-are not tracked separately and thus cannot be examined individually.

The model was initialized using Global Forecast System (GFS) analysis at 0000 UTC 9 April 2009 and integrated for $48 \mathrm{~h}$. The lateral boundaries were nudged using additional GFS analyses. The profile of those aerosols that can serve as cloud condensation nuclei $(\mathrm{CCN})$ was maximized at the surface and decreased linearly from the surface value up to $4 \mathrm{~km}$ above which it was constant at $100 \mathrm{~cm}^{-3}$. The model was run 3 times with surface aerosol concentrations of 400,800 , and $1600 \mathrm{~cm}^{-3}$; these concentrations are representative of clean, average, and polluted conditions over continents (Andreae 2009). These sensitivity runs will be referred to as $\mathrm{CCN} 400, \mathrm{CCN} 800$, and CCN1600, respectively. Apart from the differences in initial aerosol concentrations, the model setups were identical. The cloud-nucleating aerosol particles were allowed to be advected horizontally and vertically but were not depleted during cloud nucleation. To prevent runaway nucleation, aerosol particles were nucleated under appropriate environmental conditions only if their number concentration did not exceed the number concentration of cloud droplets present in the same grid box. Had the cloud-nucleating aerosol been depleted, most particles would have been rained out quickly, leaving a very clean environment in all three cases since no surface sources of aerosol were present. Additionally the aerosols were not radiatively active, so no assessment of the aerosol direct effect is made in this study.

\section{b. Synoptic overview}

Figure 1 shows output from CCN400 depicting the evolution of the storm. At 1200 UTC 9 April, a broad trough exists at both 300 and $500 \mathrm{hPa}$ over the Rocky 

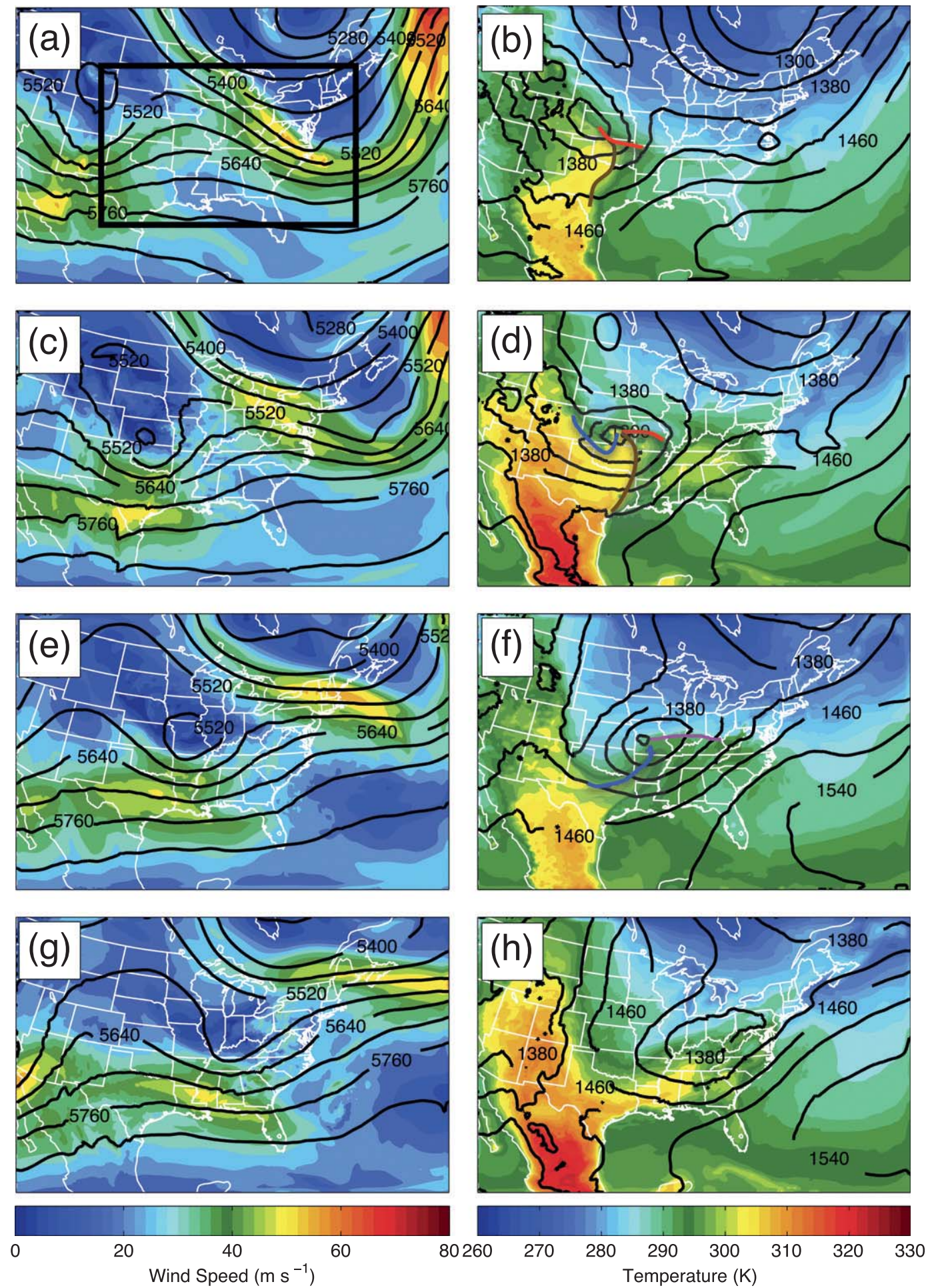

FIG. 1. (a),(c),(e),(g) Plots of 300-hPa wind speed (shaded; $\mathrm{m} \mathrm{s}^{-1}$ ) and 500-hPa geopotential height (contoured; $\mathrm{m}$ ) and (b),(d),(f),(h) surface potential temperature (shaded; K) and geopotential height (contoured; $\mathrm{m}$ ) output from the outer grid at (a),(b) 1200 UTC 9 Apr, (c),(d) 0000 UTC 10 Apr, (e),(f) 1200 UTC 10 Apr, and (g),(h) 0000 UTC 11 Apr. The red and brown lines in (b),(d) are warm fronts and drylines, respectively, and the blue line in (f) is a cold front analyzed by hand. The thick pink line in (f) is the objective location of the warm front. Fronts emanating from the storm center were not detected at the final time shown in (h). 
Mountains associated with a closed low at $850 \mathrm{hPa}$ beginning to form in eastern Colorado and western Kansas. The trough at $500 \mathrm{hPa}$ has formed a closed low, the downstream ridge has weakened, and the low at $850 \mathrm{hPa}$ has deepened $12 \mathrm{~h}$ later. There is an enhanced potential temperature gradient at $850 \mathrm{hPa}$ extending eastward from the low center, consistent with the presence of confluent background flow (Schultz et al. 1998). This is the warm front that will be the focus of this study. There is a tongue of warm air reaching the center of the circulation from the south and west that is associated with a dryline (Figs. 1b,d). This boundary was associated with a severe weather outbreak in the southeast on 9-10 April but will not be discussed in this paper.

At 1200 UTC 10 April the system is near its peak intensity. The low centers have become vertically stacked and begin to weaken shortly after this time. The warm front of interest is now associated with a distinct trough in the $850-\mathrm{hPa}$ field and its eastern end is beginning to interact with the Appalachian Mountains. The jet streak at $300 \mathrm{hPa}$ in the northeast has intensified but shifted little in the horizontal and is likely aiding in large-scale lift over the warm front. By 0000 UTC 11 April the low center is just to the west of the mountains. As it is not the objective of this study to examine the influence of the mountains on the warm front, the simulation was ended here, though the system did continue to the Atlantic Ocean and regained strength over the Gulf Stream.

Figure 2 shows a time- and space-averaged, front-normal cross section of cloud ice, cloud water, and rain from the CCN400 run of the warm front. Details on how these cross sections were created are described in section 3. The isentropes indicate that the warm front is shallow with a slope of about 1:150 and that the frontal cloud is predominantly stratiform. It can be seen that the mixedphase region is very deep, extending from about 2 to $6 \mathrm{~km}$ and that the melting level located near 2-3 km throughout most of the system.

\section{c. Validation}

Although we are simulating an actual extratropical cyclone, the goal of this research is not to present an indepth analysis of a case study. Rather, we are interested in the sensitivity of the warm front to perturbations in cloud-nucleating aerosol concentrations. As a consequence, the results are treated more like those of an idealized modeling study, where the case study data are simply used to simulate the storm type of interest, in this case an extratropical cyclone. Therefore, it is not important that the model accurately capture the time evolution or exact structure of the cyclone, only that the model simulates an extratropical cyclone that shows average characteristics that are representative of such
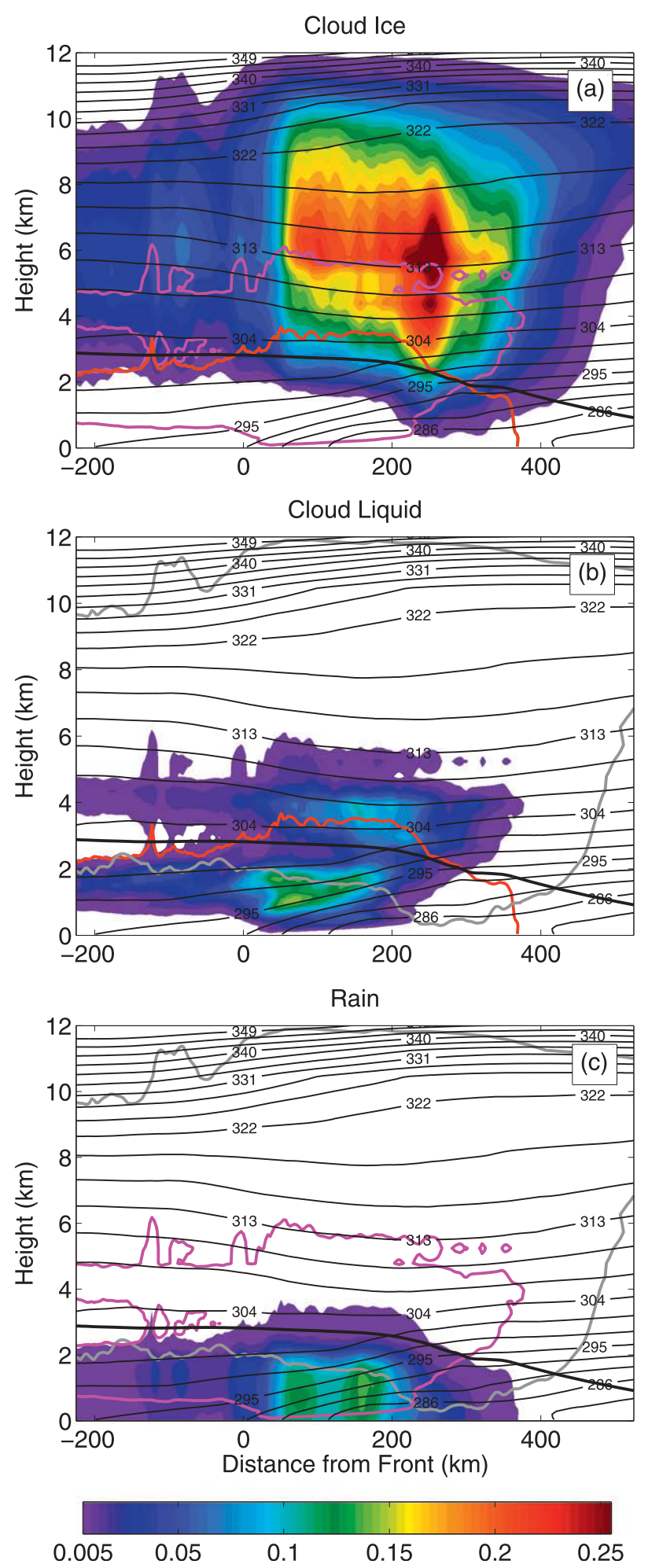

FIG. 2. Time-averaged cross-sections of (a) cloud ice, (b) cloud water, and (c) rain mixing ratio $\left(\mathrm{g} \mathrm{kg}^{-1}\right)$. Thin black lines are isentropes $(\mathrm{K})$, and the thick black line is the $0^{\circ} \mathrm{C}$ line or melting level. The gray, pink, and red lines show the $0.005 \mathrm{~g} \mathrm{~kg}^{-1}$ contours of cloud ice, cloud water, and rain, respectively, for reference. 

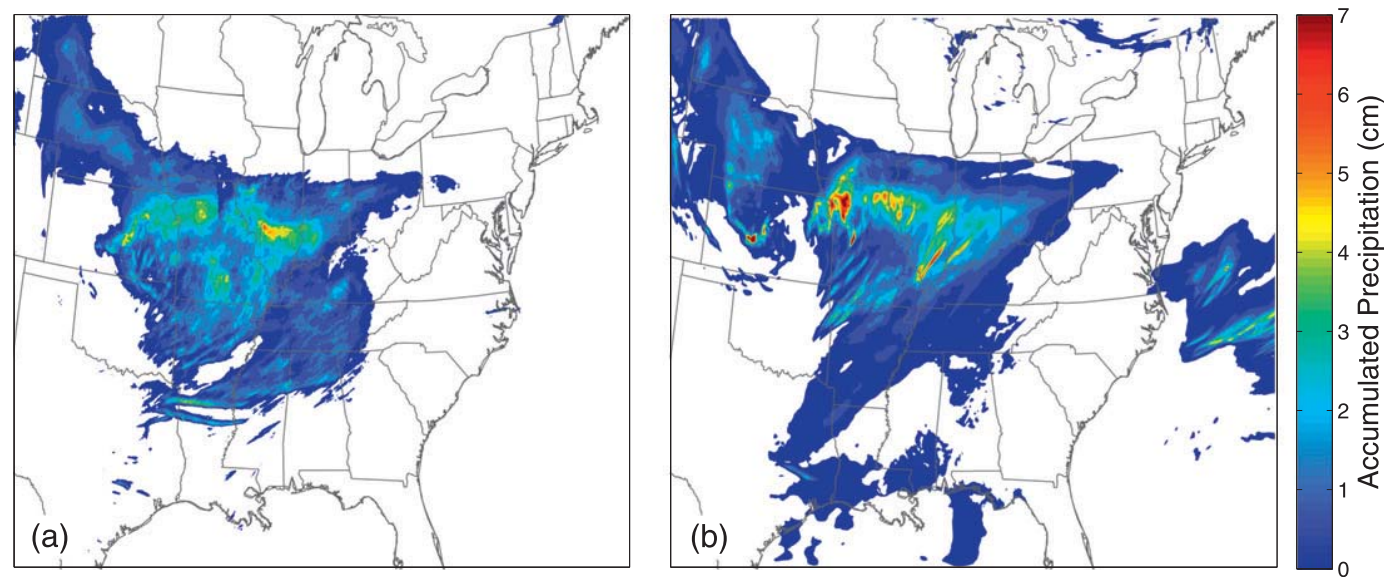

FIG. 3. (a) Radar-derived estimate of the 24-h precipitation total ending 1200 UTC 10 Apr from the National Weather Service. (b) Precipitation total for the same time period, but from RAMS output.

a system. However, it is useful to know that the model physics are to a first order correct and that the model has captured some basic features of the actual system. Total precipitation is a good field to use for this since it contains information about the storm location as well as rainfall.

Figure 3a shows the National Weather Service (NWS) Multisensor Precipitation Estimator (Lawrence et al. 2003) rainfall and Fig. $3 \mathrm{~b}$ the $\mathrm{CCN} 400$ total precipitation for the 24-h period ending 1200 UTC 10 April on the inner grid. The general pattern of precipitation is well captured, especially around the warm front. RAMS correctly places the maximum in precipitation in northern Missouri and southern Illinois and Indiana, though perhaps it is shifted slightly north and east. Comparisons of model output to NWS surface analyses also show a shift to the northeast of the modeled location of the warm front and cyclone center relative to their observed locations (not shown). The local maxima in precipitation in RAMS are higher than those seen in the radar estimate, but the average totals of $1-4 \mathrm{~cm}$ seem to be consistent. RAMS does underpredict rainfall in the southeast associated with the secondary warm front, but that is not a major concern for the analysis that will be presented here as our focus is on the primary warm front.

\section{Methods}

\section{a. Warm front detection}

To objectively locate the warm front at each hour, we used modeled potential temperature $\theta_{\text {surf }}$ and geostrophic wind velocity $V_{G_{-} \text {surf }}$, and applied the front detection algorithm of Hewson (1998) on equal-sigma surfaces rather than equal-pressure surfaces as in previous work (e.g., Naud et al. 2012). While Hewson (1998) recommended using the 900-hPa level for detecting surface fronts, we found that the surface fields were much less noisy and produced cleaner results than other near-surface levels. The technique proposed by Hewson (1998) was originally conceived for fields of about 100-km horizontal resolution, but here the resolution is $3 \mathrm{~km}$, so we had to make several adjustments. We first subsampled $\theta_{\text {surf }}$ and $V_{G_{-} \text {surf }}$ every $30 \mathrm{~km}$ and then applied a smoothing routine. These two fields were then fed into the front detection routine. Only those fronts identified by the routine with potential temperature gradients greater than $25 \times 10^{-6} \mathrm{~K} \mathrm{~m}^{-1}$ were kept, and the sign of the product of geostrophic wind velocity and potential temperature gradient delineated between warm and cold fronts.

Despite the upscaling and smoothing, multiple warm fronts were detected, and additional masks were applied to objectively isolate the primary front. Warm-frontal points along coastlines were removed. These points existed simply because of the large contrast in potential temperature between land and ocean and did not represent the warm front associated with the extratropical cyclone. Warmfrontal points were also required to have cloud cover within $60 \mathrm{~km}$ to the north in order to eliminate the boundary oriented north-south in the warm sector of the storm (Figs. 1b,d) that was associated with the severe weather outbreak mentioned earlier. Next, warmfrontal points with four or fewer neighbors within $150 \mathrm{~km}$, one or zero neighbors within $60 \mathrm{~km}$, or zero neighbors within $300 \mathrm{~km}$ in the next hour were thrown out. The effects of these conditions were to remove short-lived warm-frontal structures. Finally, a $10^{\circ}$ polynomial was fit to the remaining warm-frontal points in order to preserve the shape and location of the warm front while smoothing clusters of points and to recover the original 3-km inner grid resolution. 


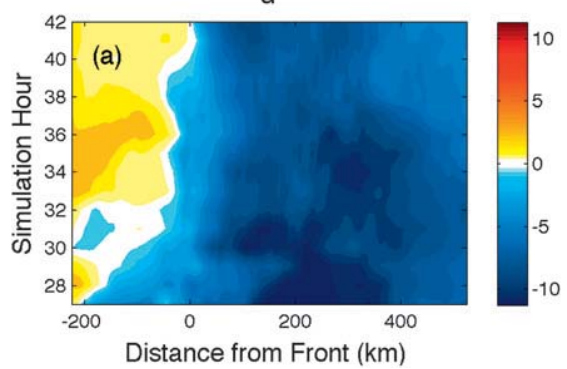

$\mathrm{V}$

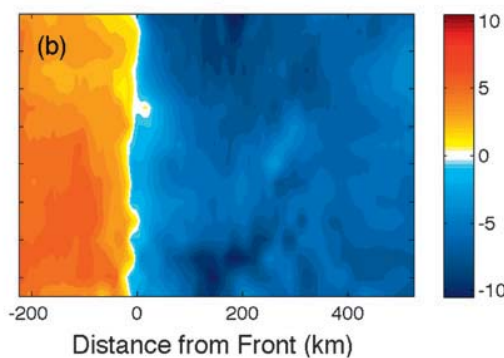

Potential Temperature

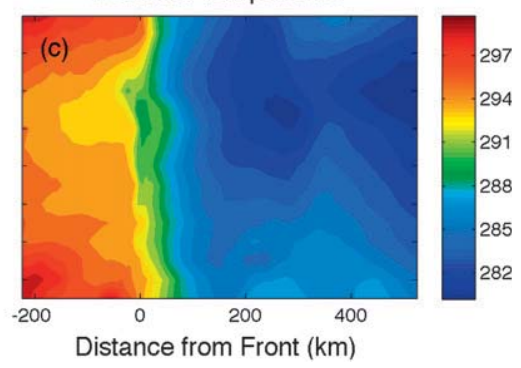

FIG. 4. Hovmöller diagrams of the model average $u, v$, and potential temperature at the surface as a function of distance from the warm front. See text for further details.

The final objective locations of the warm front at each hour (see, for example, the one in Fig. 1f) show that the detection algorithm effectively locates the warm front such that it is continuous in time. It performs best from hours 27-42 of the simulation during which time almost the entire length of the front propagates forward at each time step. It is over this interval that the analyses presented here will be conducted.

\section{b. Averaging}

The objective warm-front locations were used to create average cross sections through the front. The distance to the storm center and length of the front varies in time. However, to maintain a consistent data volume for each time, warm fronts were defined to begin $60 \mathrm{~km}$ east of the low pressure center (the largest distance between the low pressure center and the first point of any objective front) and to be $573 \mathrm{~km}$ long (the length of the shortest front in the simulation). The warm fronts are nearly parallel to the west-east direction at each time step (Fig. 1f, for example), so no rotation of the data was necessary. Model output was taken along a north-south transect at each grid point along the front and averaged along the eastwest direction to obtain a single composite cross section perpendicular to the front at each hour. The meridional span captured the bulk of the precipitation and cloud field associated with the warm front. Figure 4 shows Hovmöller diagrams of the zonal wind $u$, the meridional wind $v$, and potential temperature at the surface as a function of distance from the front. It can be seen that the warmfront detection and averaging correctly places the front on the warm side of the baroclinic zone and that the cross-front wind shifts from positive to negative as expected. This indicates that the front detection and averaging is effectively capturing the features of the front.

In many studies of aerosol indirect effects, quantities are averaged only over regions where some definition of cloud is met. However, in this study no minimum threshold for condensate is used in any of the averaging of cloud processes or cloud properties since cloud and/or precipitation are present in most of the subsetted domain (Fig. 2). In this way, the number of points being averaged is the same in each case and any differences between simulations must be due to actual changes in the quantity being shown, rather than changes in sample size. The exceptions are hydrometeor diameters, which are averaged only where they are nonzero and are weighted by the number concentration of the proper species. All vertical profiles shown in the figures to follow are averaged from the surface location of the front to $525 \mathrm{~km}$ north of the front. Areas immediately south of the surface front did not receive substantial precipitation and therefore were not included in the averages. By averaging to $525 \mathrm{~km}$ ahead of the front, nearly the full extent of the warm-frontal cloud is captured, though at its farthest reaches, only ice exists and liquid species are not present (Fig. 2).

\section{Cloud budgets}

Figure 5 shows average vertical profiles of each of the most important processes contributing to the production or depletion of ice species, cloud water, and rain in CCN400. The ice budget (Fig. 5a) shows that vapor deposition is the dominant growth process above about $4.5 \mathrm{~km}$ whereas riming is dominant below that level. This being a warm spring case (Fig. 1), very little ice reaches the surface in the simulation and therefore most ice that is produced must eventually melt. Sublimation and the collection of ice by rain are minor sinks of ice compared to melting. These results lie between the two cases examined by Rutledge and Hobbs (1983). In the feeder zone of their weak updraft case they found no contribution to the ice budget by riming, whereas in the feeder zone of their mesoscale updraft case they found the riming rate to be 2-3 times greater than the depositional growth rate.

Neither the study by Rutledge and Hobbs (1983) nor that by Gedzelman and Arnold (1993) examined the cloud water budget. The cloud water budget in this study 

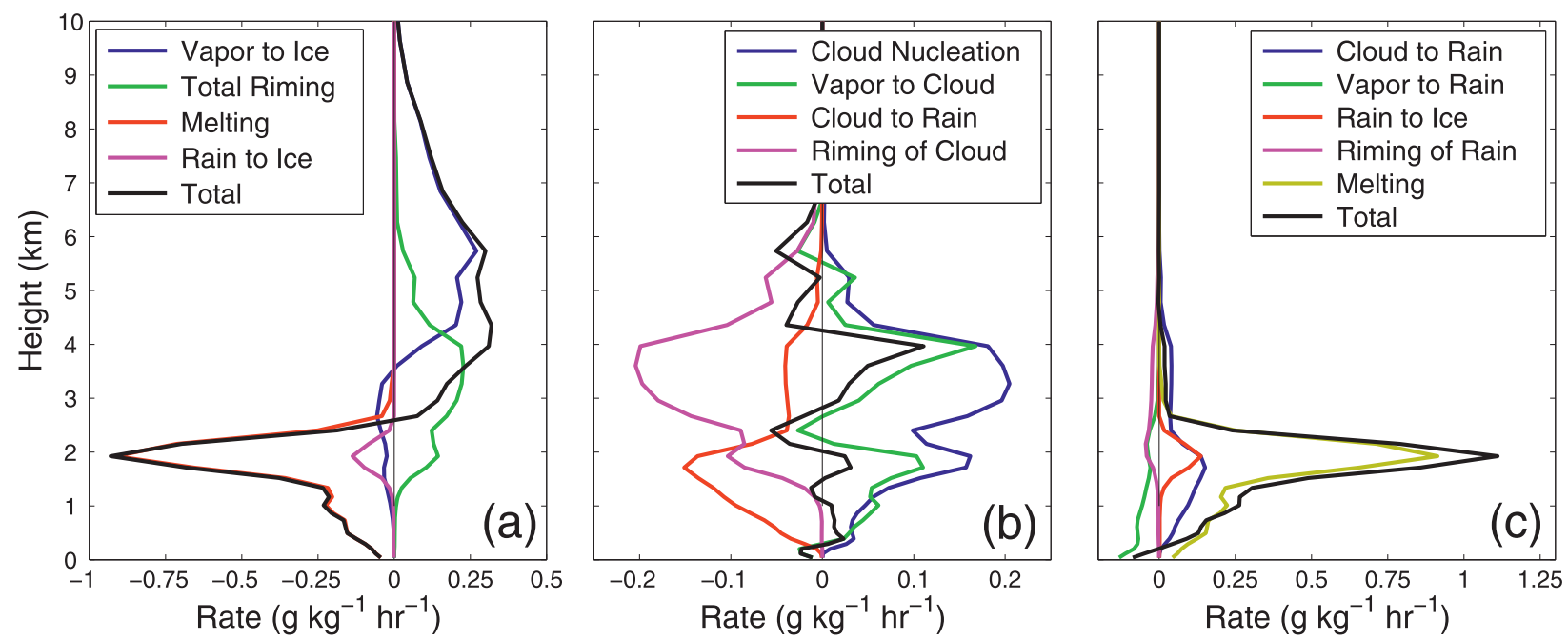

FIG. 5. Vertical profiles of each of the major processes contributing to the budget of (a) ice, (b) cloud water, and (c) rain. Note the melting level is near $2 \mathrm{~km}$. Positive (negative) values indicate growth (decay) of the species. See the text for a full description of each process.

(Fig. 5b) shows two peaks in production, one in the mixed-phase region of the cloud near $4 \mathrm{~km}$ and one just below the melting level near $2 \mathrm{~km}$. The upper peak appears to be caused by updrafts creating supersaturated conditions while the lower peak may exist because of supersaturated conditions being created by the latent cooling due to melting. The cloud nucleation rate is slightly greater than the condensational growth rate at both peaks and significantly greater in the region between the peaks. The main process contributing to the depletion of cloud water at each peak is different. At the upper peak, cloud-droplet-to-rain conversion rates are small and riming rates dominate. However at the lower peak, cloud droplet to rain conversion rates are larger than the riming rate, though riming is still significant at the melting layer. Cloud droplet sizes and rain mixing ratios are both much smaller at the upper peak (Fig. 6), which would reduce the rates of autoconversion and accretion. When integrated through the column, riming contributes about $33 \%$ more to the depletion of cloud water than do cloud to rain conversion processes.

Finally the rain budget is shown in Fig. 5c. Melting of ice is by far the most important producer of rainwater, a result found by both Rutledge and Hobbs (1983) and Gedzelman and Arnold (1993). The conversion of cloud water to rain is of secondary importance. The budgets show that about $75 \%$ of rain mass is due to melting of ice, where half of the ice mass is formed through depositional growth and half through the riming of cloud water. The remaining roughly $25 \%$ of rain mass is produced through warm rain processes in this case. The seeder-feeder process is thought to be responsible for the enhancement of precipitation in warm-frontal rainbands (Houze et al. 1981; Rutledge and Hobbs 1983). Though no distinction has been made between banded and nonbanded precipitation in this study, these results also suggest that ice crystals falling through the mixed-phase region of the cloud efficiently collect cloud water that would not otherwise be converted to rain; this collection contributes significantly to the total precipitation.

\section{Sensitivity to changes in cloud-nucleating aerosol concentrations}

\section{a. Microphysical cloud properties}

The sensitivity of the mass budgets and cloud properties to increases in cloud-nucleating aerosol concentrations will now be discussed by comparing results from the CCN400, CCN800, and CCN1600 simulations. Figure 6 shows average vertical profiles of hydrometeor number concentration, mixing ratio, and diameter in the top three rows. The percentage change from $\mathrm{CCN} 400$ to $\mathrm{CCN} 1600$ in these quantities is shown in the bottom row. As discussed in section 2a, pristine ice, snow, and aggregates (PSA) have been averaged together, the mixed-phase species $(\mathrm{GH})$ are combined, as are the two cloud droplet modes. Although the responses of each ice species to the sensitivity tests differ, grouping them in this way shows the overall impact of changes in aerosol concentrations. The PSA number concentration, diameter, and mixing ratio are dominated by aggregates below $8 \mathrm{~km}$. It is important to note that profiles of mixing ratio are not expected to match the total budget profiles in Fig. 5 

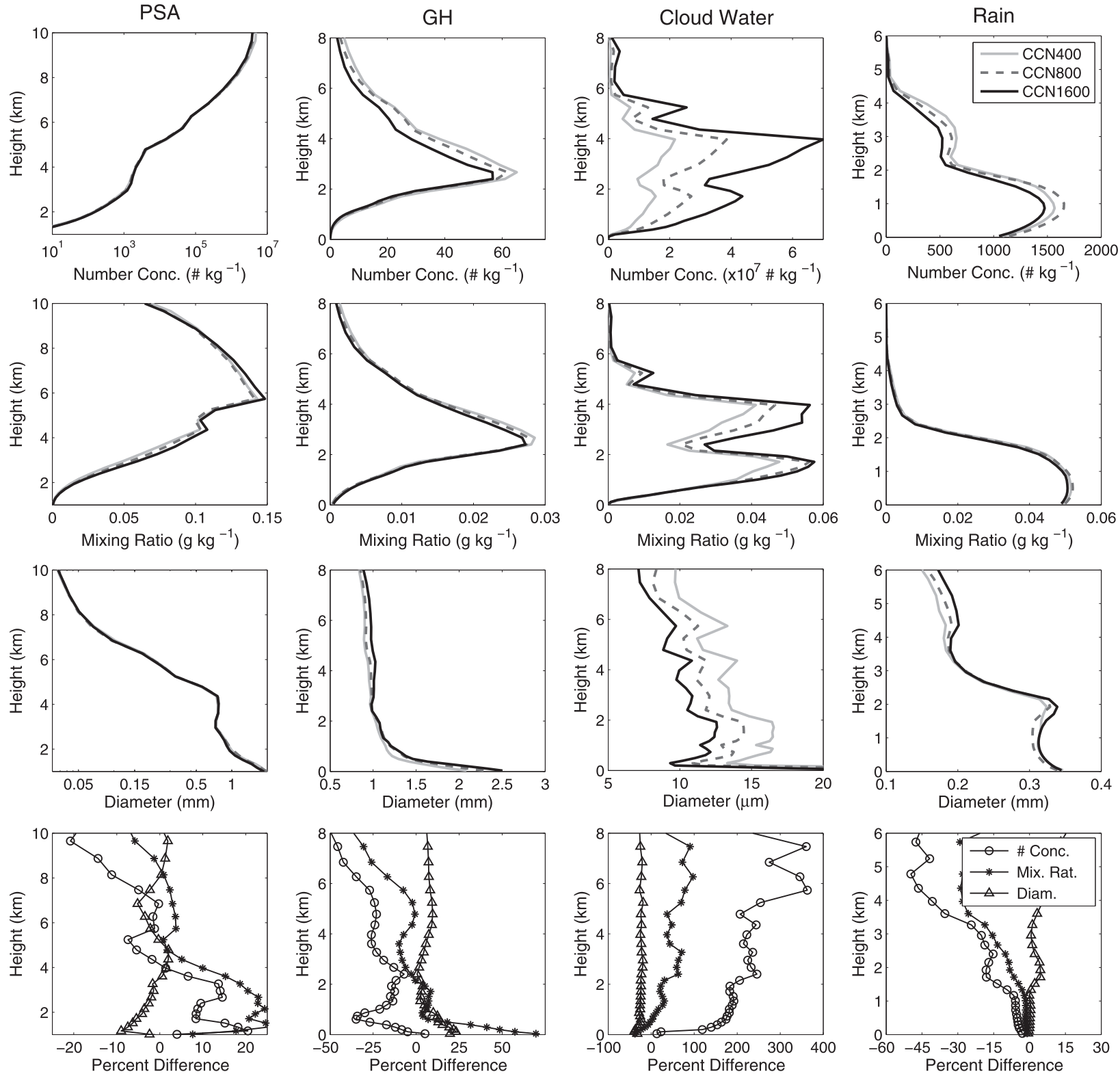

FIG. 6. Average vertical profiles of (top row) number concentration, (second row) mixing ratio, and (third row) number concentration for each of the four groups of hydrometeors described in the text. Diameters were averaged only where they were nonzero and weighted by number concentration, but no minimum threshold was used in averaging number concentrations or mixing ratios. (bottom row) The percentage change of CCN1600 from CCN400 for number concentration, mixing ratio, and diameter of each hydrometeor group.

since advection and sedimentation were not included in the budget calculations.

With increasing pollution cloud droplets are more numerous and smaller which is expected according to the cloud albedo effect (Twomey 1977), and the overall cloud water path is increased. PSA mixing ratio is highest in CCN1600 below $8 \mathrm{~km}$, though CCN400 and CCN800 are similar; the trend becomes clearly monotonic at $4 \mathrm{~km}$ and below. Fewer GH particles exist with enhanced aerosol concentrations although the differences in number are nearly zero below the melting level. Overall there is less mass in this category above the melting level in the more polluted cases, but again, below the melting level differences are very small. Throughout the column, rain exhibits very little variation in mixing ratio among the three simulations. There are monotonic trends in number concentration above $2 \mathrm{~km}$ where drops are less numerous but below $2 \mathrm{~km}$, the trend is nonmonotonic. There is also no appreciable variation in rain droplet size in the lowest $4 \mathrm{~km}$ of the column. 


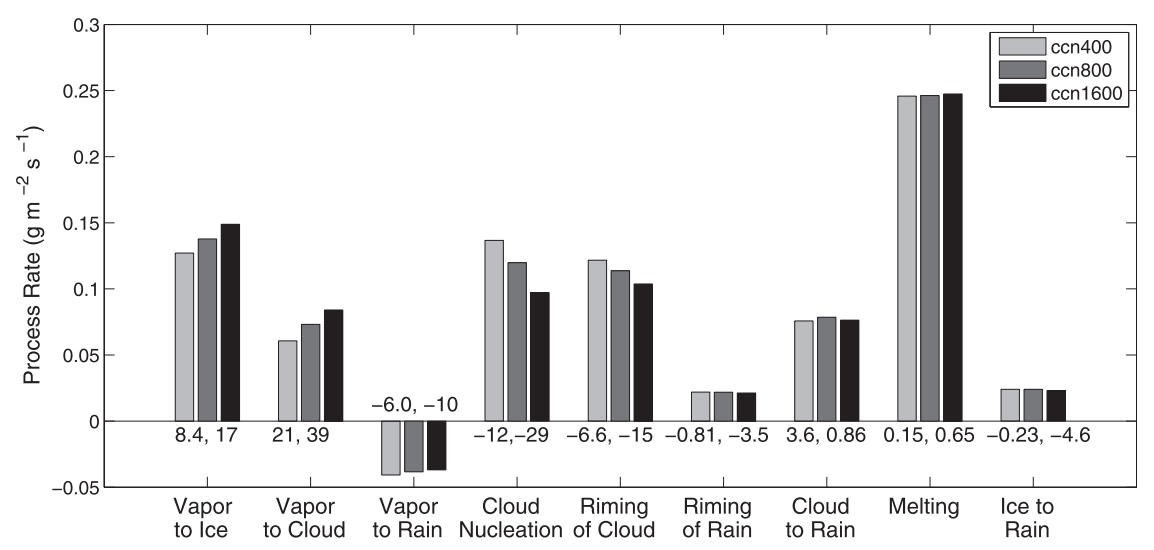

FIG. 7. Vertically integrated and averaged rates of each of the major water budget processes. The two numbers printed with each process are the percentage change of CCN800 and CCN1600, respectively, from the CCN400 value.

Insight into these differences in cloud properties can be gained by examining the changes in budget terms (Fig. 7). Cloud condensation rates increase, but not enough to compensate for the decrease in cloud nucleation rates, such that there is less production of cloud water with increasing cloud-nucleating aerosol concentrations. The trends in these two terms oppose one another since nucleation and condensation compete for the available water vapor. In the more polluted cases, total condensational growth increases because of the increased total surface area of the more numerous but smaller cloud droplets (not shown). This change effectively decreases the supersaturation and inhibits cloud nucleation. The overall increase in cloud water mixing ratio seen previously is ultimately a result of decreased riming caused by the decreased size of the cloud droplets.

There are many similarities between warm-frontal and orographic clouds-a sloped surface, weak to moderate updraft speeds and the presence of a mixed phase to name three-such that a comparison with results from orographic cloud sensitivity studies is useful. The trends in the three terms discussed above are consistent with the results of Saleeby et al. (2009) who looked at the impacts of $\mathrm{CCN}$ on an orographic snowfall case. In their study though, they found decreased sensitivity to riming rates for $\mathrm{CCN}$ concentrations above $500 \mathrm{~cm}^{-3}$, whereas in the present study significant decreases in riming are seen even for the CCN1600 case (Fig. 7).

Interestingly, there is very little change in cloud-torain processes across the three simulations such that they do not contribute to changes in mixing ratio of cloud water or rain. The same result was seen in one of the simulations of an orographic mixed-phase rain case examined by Muhlbauer et al. (2010). However, this result is in contrast with other purely warm rain studies that show suppressed rain formation in polluted scenarios (e.g., Albrecht 1989; Xue and Feingold 2006; Saleeby et al. 2010). Figure 8 shows average vertical profiles of the rain mass produced through cloud-cloud collisions (autoconversion, Fig. 8a) and the rain mass growth through cloud-rain collisions (accretion, Fig. 8b). It can be seen that the autoconversion of cloud droplets to rain decreases as expected because of the smaller cloud droplet size, but that the accretion of cloud droplets by rain increases with increasing aerosol concentrations. Since formation of raindrops in this case occurs primarily through melting, they can gain large sizes without growing through autoconversion of cloud water. Collision efficiency between cloud droplets and raindrops is not usually very sensitive to cloud droplet size, so rain drops will be able to accrete more cloud water in the more polluted cases despite decreases in cloud droplet size since more cloud water mass is available because of the decreased autoconversion. It is unclear whether the nearly exact cancellation between cloud droplet autoconversion and cloud-rain collisions in this case is fortuitous or not. Additionally, note that about twice as much rain mass is gained through cloud-rain collisions than through autoconversion. This reemphasizes the fact that very little rain is being produced independent of ice processes.

In the more polluted simulations PSA mixing ratio increases while that of $\mathrm{GH}$ decreases, as discussed above. The budget terms in Fig. 7 show that vapor deposition increases, while riming decreases with increasing aerosol concentrations. Vapor deposition occurs primarily on the PSA species, so the increase in that process alone can explain the increase in PSA mass. Most of the change in vapor deposition is confined to the mixed-phase region of the cloud (Fig. 8c). This change in vapor deposition may 

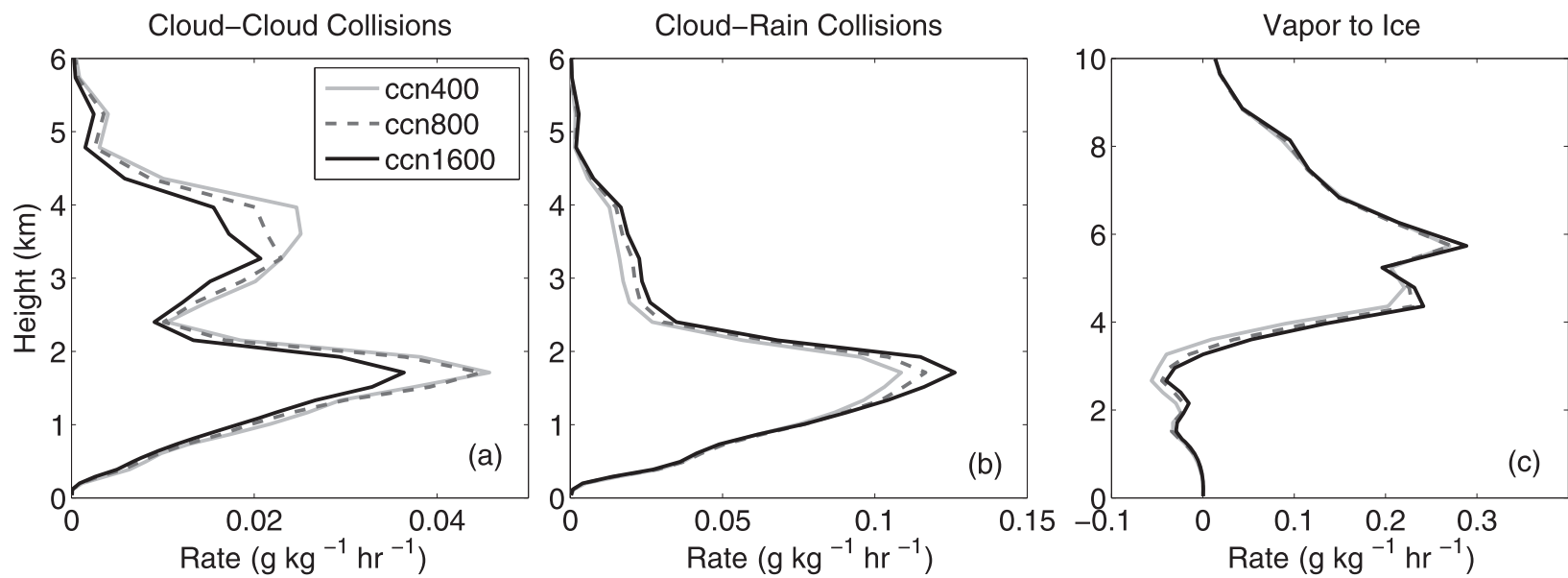

FIG. 8. Average vertical profiles of (a) rain mass growth through cloud-cloud collisions (autoconversion), (b) rain mass growth through cloud-rain collisions (accretion), and (c) ice mass growth and decay through vapor deposition and sublimation.

be due to an alteration in the competition for vapor between liquid and ice particles in this region because of changes in the size and number of cloud droplets. In addition, riming is one pathway for the conversion of PSA to $\mathrm{GH}$; therefore, the decrease in riming further explains the increase of PSA mass as well as the decrease in GH mass with increasing aerosol concentrations above the melting level. At and below the melting level, remaining PSA mass is quickly converted to $\mathrm{GH}$ and then to rain (Walko et al. 1995). The changes in vapor deposition and riming almost exactly cancel one another, so below the melting level there are no significant differences in the surviving ice mass or in the rain mass produced through melting.

The two largest contributors to rain mass, melting and collision-coalescence, both show little sensitivity to cloud-nucleating aerosol concentration, as discussed above. This explains why there is also little change in rain mixing ratio below the melting level across the three simulations. As would be expected in association with this result, there are also only small changes in the average precipitation rates (Table 1).

\section{b. Local precipitation changes}

Although on average the precipitation rates are not very sensitive to aerosol concentration, there are larger changes seen locally. Fig. 9a shows the time averaged precipitation rates as a function of distance from the front. The largest changes are seen between 50-200 km from the front where there is on average a $9.5 \%$ difference between $\mathrm{CCN} 400$ and $\mathrm{CCN} 1600$; however, the trends are often nonmonotonic and it is difficult to attribute any specific processes to the changes. Therefore we would not expect the location of these changes to be a general result of this study.
Figure $9 \mathrm{~b}$ again shows time-averaged precipitation rates but excludes those rates greater than $5 \mathrm{~mm} \mathrm{~h}^{-1}$ that may be associated with more convective-type processes. The local maxima in CCN400 and CCN1600 in Fig. 9a around $50 \mathrm{~km}$ from the front are effectively removed and much clearer trends in precipitation are revealed. There is a delay in the onset of precipitation with increasing cloud-nucleating aerosol concentration such that precipitation is initially shifted about $15-20 \mathrm{~km}$ downwind of the front. This is similar to the "spillover effect" seen in many orographic snow cases in which precipitation is shifted to the leeward side of a mountain in more polluted conditions (e.g., Givati and Rosenfeld 2004; Jirak and Cotton 2006; Lynn et al. 2007; Saleeby et al. 2009). However, farther from the front rain rates in the two more polluted simulations have higher intensities at their peaks. Just after these peaks, rain rates are similar across all three cases. Because of the changes in peak rain rates, the difference in average rainfall is still only $2.0 \%$ between CCN400 and CCN800 and $1.4 \%$ between CCN400 and CCN1600. These are not significant changes in precipitation. This is in contrast to some orographic sensitivity studies which generally find decreases in the overall precipitation because of losses through sublimation of snow and ice crystals on the lee side of the mountain (Lynn et al. 2007). However, in this case, since there is little precipitation where sublimation

TABLE 1. Summary statistics of precipitation rate.

\begin{tabular}{lcc}
\hline Simulation & $\begin{array}{c}\text { Precipitation rate } \\
\left(\mathrm{mm} \mathrm{h}^{-1}\right)\end{array}$ & $\begin{array}{c}\text { Change from } \\
\text { CCN400 }(\%)\end{array}$ \\
\hline CCN400 & 1.041 & - \\
CCN800 & 1.056 & 1.4 \\
CCN1600 & 1.06 & 2.1 \\
\hline
\end{tabular}



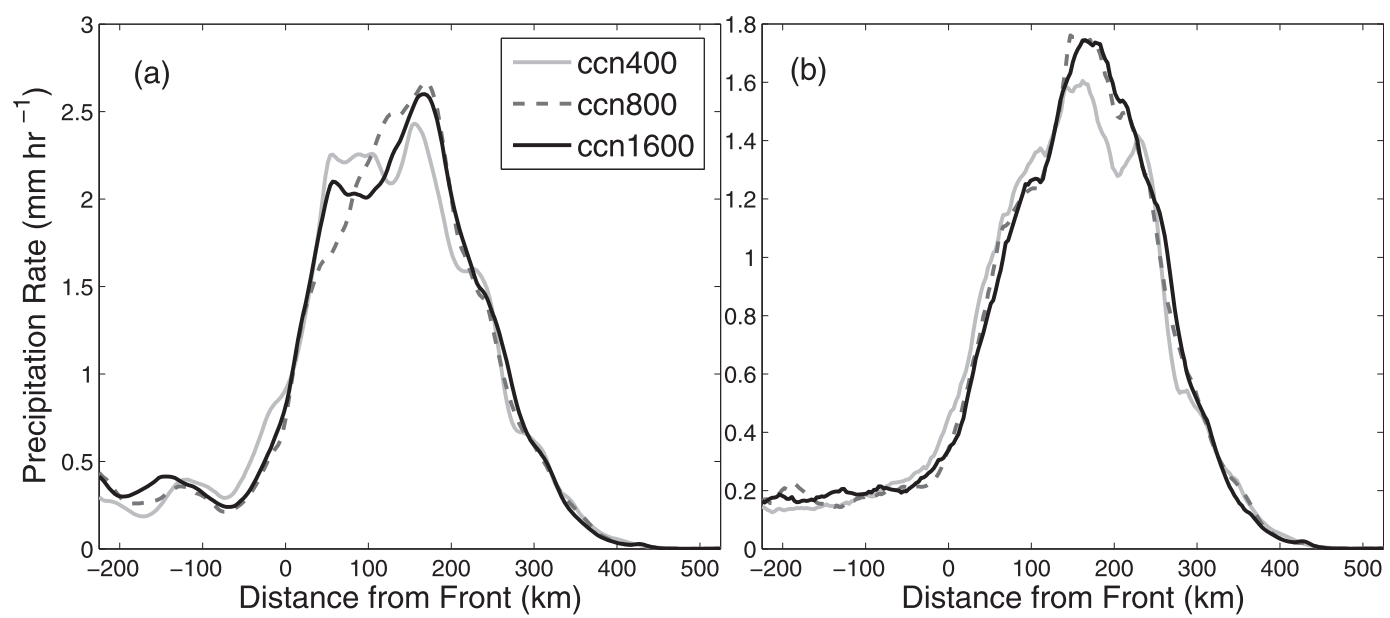

FIG. 9. (a) The average precipitation rate as a function of distance from the front. (b) As in (a), but excluding precipitation rates greater than $5 \mathrm{~mm} \mathrm{~h}^{-1}$.

of ice and evaporation of cloud water is substantial, precipitation cannot be reduced significantly through these processes.

Examination of the vertically integrated processes contributing to rain formation in areas where the rain rate is $5 \mathrm{~mm} \mathrm{~h}^{-1}$ or less (Fig. 10) shows that both cloud water conversion to rain and melting are suppressed near the front. The suppression from melting is not seen between the CCN800 and CCN1600 cases, but suppression is still clearly evident in the cloud-to-rain processes. It is not immediately obvious why there is so little difference in melting between CCN800 and CCN1600, especially since riming does not show the same insensitivity. However, the GH particles are larger in CCN1600 and their faster sedimentation rates may be off setting the decrease in mass because of decreases in riming rates. The increased peak in precipitation in CCN800 and CCN1600 farther downwind appears to be because of enhancements in both melting and cloud-to-rain processes at these locations.

\section{c. Latent heating and warm-frontal structure}

The total latent heating (Fig. 11) shows only small differences among the experiments, despite the fact that significant changes were seen in the rates of many cloud processes. There are increases up to $1 \mathrm{~km}$, and again between about 3 and $3.5 \mathrm{~km}$. The increase at this latter level is about $45 \%$ from CCN400 to CCN1600, which is quite significant, although very localized. Decreases are seen around the melting level as well as near $4 \mathrm{~km}$. When vertically integrated, the difference between CCN400 and CCN1600 is only $1.5 \%$. This implies that though changes in warm-frontal latent heating from specific cloud processes vary significantly, they largely cancel one another when summed.
Finally, vertical profiles of vertical velocities are shown in Fig. 12. There is on average a small $(3 \%-5 \%)$ increase in vertical velocity throughout the column with increasing aerosol concentrations. Increases in updraft speed (Fig. $12 b)$ are only seen in CCN1600 and only between about 4 and $6 \mathrm{~km}$, possibly because of the localized increase in
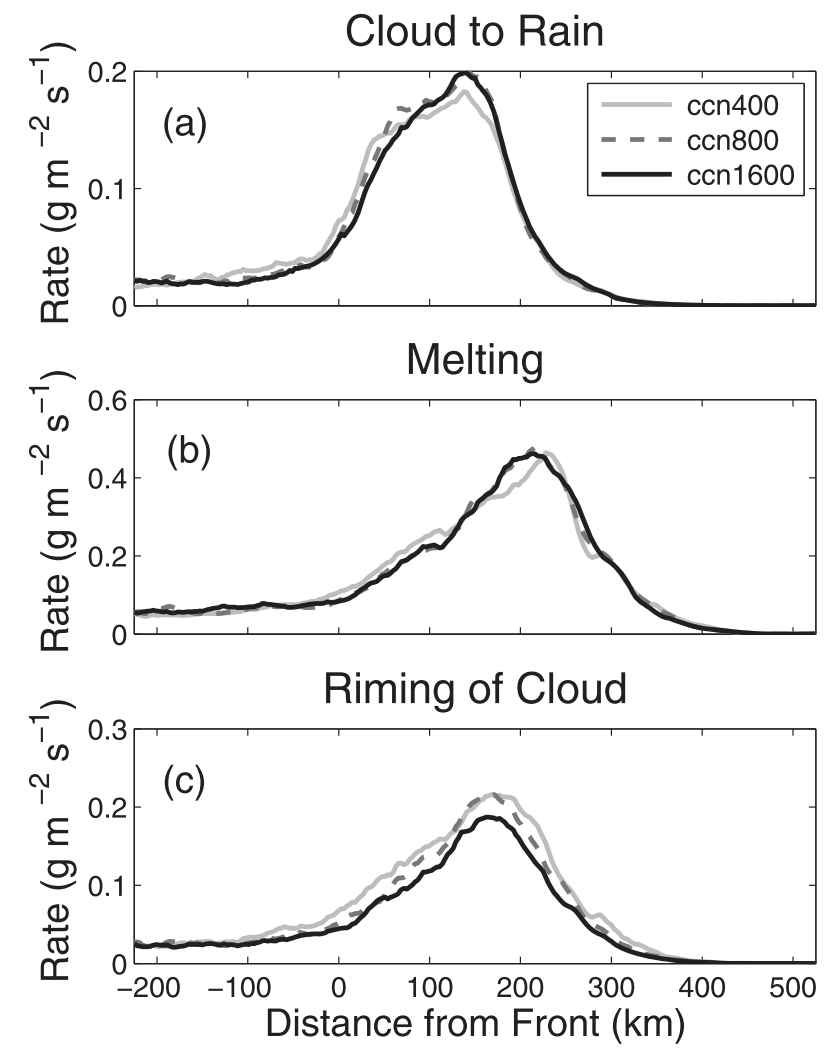

FIG. 10. Vertically integrated and averaged values of selected process rates as a function of distance from the front. 


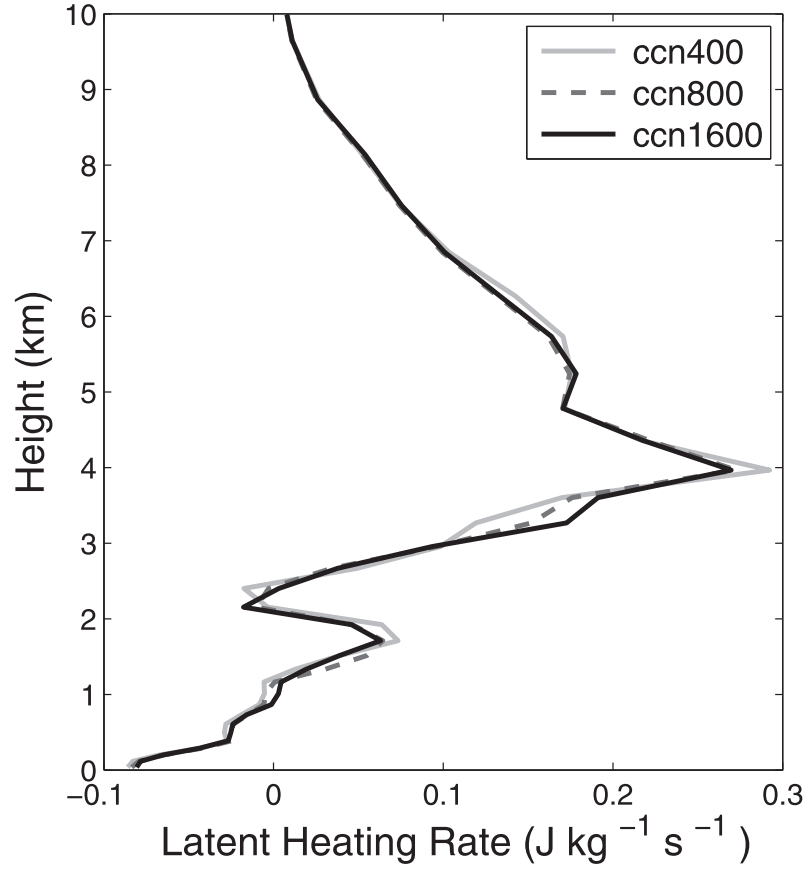

FIG. 11. Average vertical profiles of the total latent heating rate.

latent heating seen from 3 to $3.5 \mathrm{~km}$. Also note that the level of maximum latent heating is below that of maximum vertical velocity. This may be due to lower vapor availability where updrafts are stronger aloft. Downdrafts (Fig. 12c) show more variability and clear, monotonic trends are not evident. Overall, the changes to average vertical velocity are small and do not seem to have had significant impacts on the warm front as a whole.

\section{Conclusions}

RAMS was successfully used to simulate the impacts of increased aerosol concentrations on a springtime extratropical cyclone that developed and crossed the United States from 9 to 11 April 2009. Although we simulated an actual case, the results of the aerosol sensitivity tests can be treated in an idealized framework. First, the budgets of cloud ice, cloud water, and rain were examined over the warm front. Vapor deposition and riming both contribute significantly to the total ice mass in this case since updraft speeds were high enough to sustain a deep mixed-phase cloud region. Riming is the most significant sink of cloud water, especially in the mixed-phase region. The melting of ice species produces $75 \%$ of the rain with the other $25 \%$ coming from conversion of cloud droplets to rain. The exact contribution from each of these processes varies as a function of distance from the front, as seen in Fig. 10, with conversion of cloud droplets being fairly constant from 25 to $175 \mathrm{~km}$ ahead of the front and melting peaking sharply at $200 \mathrm{~km}$ ahead of the front. These results, while specific to the case analyzed here, do generally agree with the studies of Rutledge and Hobbs (1983) and Gedzelman and Arnold (1993) who both also examined cases in which rain was the predominant hydrometeor reaching the surface. This suggests that the results presented here are robust for warm fronts in which the seeder-feeder process is dominant. The budgets would be expected to differ for colder systems that do not produce rain, or for systems in which convection is more prominent.

Three sensitivity experiments were conducted in which the profiles of cloud-nucleating aerosol concentrations decreased linearly to $100 \mathrm{~cm}^{-3}$ at $4 \mathrm{~km} \mathrm{AGL}$ starting with surface concentrations of 400,800 , and $1600 \mathrm{~cm}^{-3}$. There is a slight shift seen in the distribution of light to moderate precipitation rates where less precipitation falls with increasing aerosol concentration at the surface position of the front, but more falls between 100 and $200 \mathrm{~km}$ from the front. In total there is a mere $2 \%$ increase in the temporally and spatially averaged warm-frontal precipitation from CCN400 to CCN1600.

Significant changes in association with variations in aerosol concentrations are seen in many processes that contribute to the production and depletion of cloud
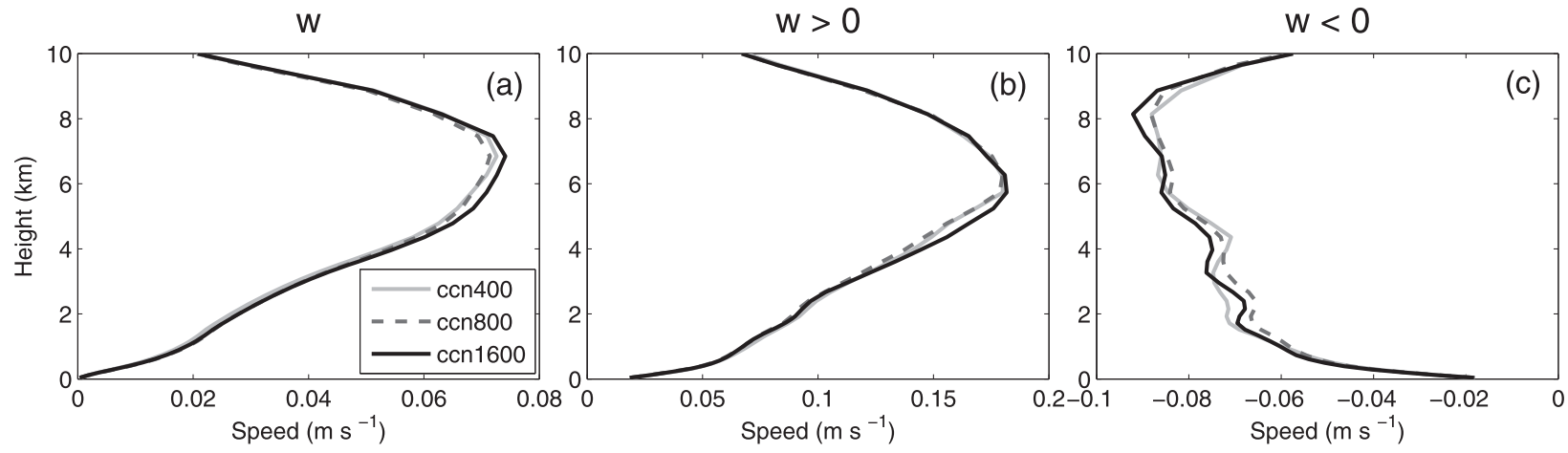

FIG. 12. Average vertical profiles of (a) total vertical velocity, (b) updrafts, and (c) downdrafts. 


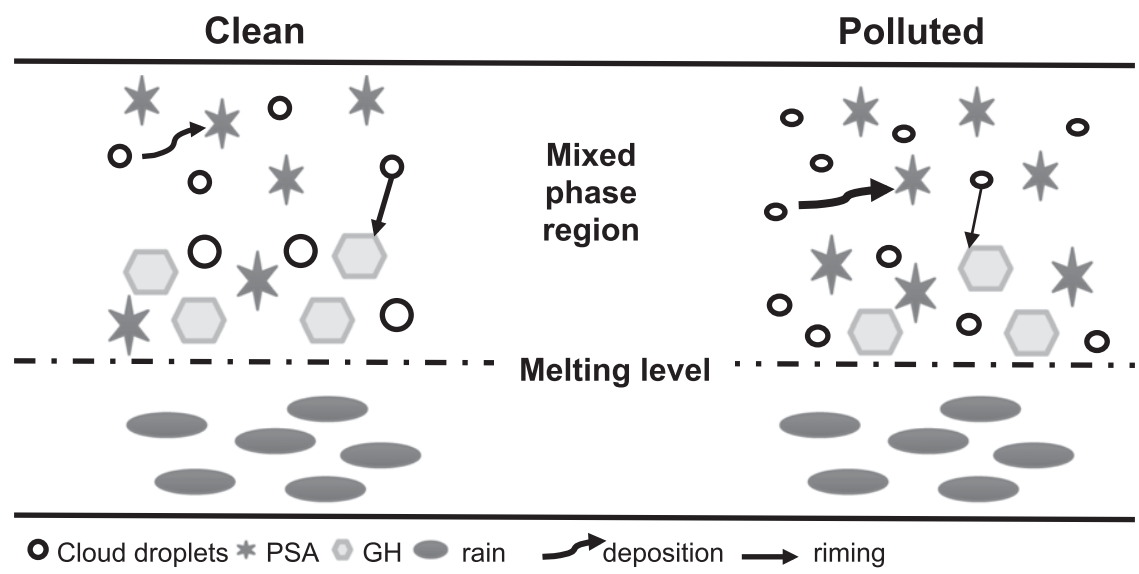

FIG. 13. Summary schematic showing the changes to the microphysical properties of the mixed-phase portion of the warm-frontal cloud and the total precipitation. Vapor deposition onto pristine ice, snow, and aggregates (PSA) increases (as indicated by the change in arrow thickness) while riming of the mixed-phase species $(\mathrm{GH})$ decreases. These two trends in the growth of ice mass cancel one another resulting in little change in total ice mass and little change in rain production through melting. Differences in size and number of hydrometeors between the clean and polluted scenarios indicate qualitative changes.

water and ice, but not of rain. A simple schematic is shown in Fig. 13 that summarizes these results. Because of higher cloud-nucleating aerosol concentrations, cloud droplets are smaller and more numerous. In the mixedphase region of the cloud, these changes in the cloud droplet distribution appear to cause enhanced deposition of vapor onto PSA crystals but decrease riming by $\mathrm{GH}$ species. The responses of vapor deposition and riming tend to cancel one another such that similar amounts of total ice are produced, causing little change in rain production from melting, which is the most important source of rain in warm-frontal clouds. This suggests that the mixed-phase part of the cloud has compensating responses that limit the impact of increased cloud-nucleating aerosols on surface precipitation. In addition, the compensating responses in cloud processes prevent large changes in total latent heating. As a result, cloud-nucleating aerosols do not appear to be able to play a strong role in determining the total precipitation, average latent heating, or average vertical velocities of warm fronts.

Only one case of a spring-season, mostly stratiform warm front was examined in the present study, and it is unclear whether these results can be generalized to all warm fronts. The response of more convective fronts or colder systems with less liquid water may be different, as may the response to ice nuclei or giant $\mathrm{CCN}$ for storms over the ocean. Investigation into these questions is left for future work. However, an increasing number of sensitivity studies (Stevens and Feingold 2009; Muhlbauer et al. 2010; van den Heever et al. 2011; Seifert et al. 2012), including the one here, are finding that the mixed phase of cloud systems provide built-in buffers that resist wide-scale changes in aerosol concentrations. This trend lends support to the robustness of the conclusions presented here.

Acknowledgments. The authors thank the anonymous reviewers for their constructive comments that have led to great improvements in the manuscript. This research was supported by NASA Grant NNX10AM20G.

\section{REFERENCES}

Albrecht, B. A., 1989: Aerosols, cloud microphysics, and fractional cloudiness. Science, 245, 1227-1230.

Andreae, M. O., 2009: Correlation between cloud condensation nuclei concentration and aerosol optical thickness in remote and polluted regions. Atmos. Chem. Phys., 9, 543-556.

Borys, R. D., D. H. Lowenthal, S. A. Cohn, and W. O. J. Brown, 2003: Mountaintop and radar measurements of anthropogenic aerosol effects on snow growth and snowfall rate. Geophys. Res. Lett., 30, 1538, doi:10.1029/2002GL016855.

Catto, J. L., C. Jakob, G. Berry, and N. Nicholls, 2012: Relating global precipitation to atmospheric fronts. Geophys. Res. Lett., 39, L10805, doi:10.1029/2012GL051736.

Cheng, C.-T., W.-C. Wang, and J.-P. Chen, 2010: Simulation of the effects of increasing cloud condensation nuclei on mixedphase clouds and precipitation of a front system. Atmos. Res., 96, 461-476, doi:10.1016/j.atmosres.2010.02.005.

Clough, S. A., H. W. Lean, N. M. Roberts, and R. M. Forbes, 2000: Dynamical effects of ice sublimation in a frontal wave. Quart. J. Roy. Meteor. Soc., 126, 2405-2434.

Cotton, W. R., and Coauthors, 2003: RAMS 2001: Current status and future directions. Meteor. Atmos. Phys., 82, 5-29.

Fan, J., and Coauthors, 2009: Dominant role by vertical wind shear in regulating aerosol effects on deep convective clouds. J. Geophys. Res., 114, D22206, doi:10.1029/2009JD012352. 
Garvert, M. F., C. P. Woods, B. A. Colle, C. F. Mass, P. V. Hobbs, M. T. Stoelinga, and J. B. Wolfe, 2005: The 13-14 December 2001 IMPROVE-2 event. Part II: Comparisons of MM5 model simulations of clouds and precipitation with observations. J. Atmos. Sci., 62, 3520-3534.

Gedzelman, S. D., and R. Arnold, 1993: The form of cyclonic precipitation and its thermal impact. Mon. Wea. Rev., 121, 1957-1978.

Givati, A., and D. Rosenfeld, 2004: Quantifying precipitation suppression due to air pollution. J. Appl. Meteor., 43, 1038-1056.

Harrington, J. Y., 1997: The effects of radiative and microphysical processes on simulation warm and transition season Arctic stratus. Ph.D. dissertation, Colorado State University, 289 pp. [Available from Department of Atmospheric Science, Colorado State University, Fort Collins, CO 80523.]

Hewson, T. D., 1998: Objective fronts. Meteor. Appl., 5, 37-65.

Hill, G. E., 1974: Factors controlling the size and spacing of cumulus clouds as revealed by numerical experiments. J. Atmos. Sci., 31, 3909-3927.

Houze, R. A., S. A. Rutledge, T. J. Matejka, and P. V. Hobbs, 1981: The mesoscale and microscale structure and organization of clouds and precipitation in midlatitude cyclones. III: Air motions and precipitation growth in a warm-frontal rainband. J. Atmos. Sci., 38, 639-649.

Hsie, E.-Y., R. A. Anthes, and D. Keyser, 1984: Numerical simulation of frontogenesis in a moist atmosphere. J. Atmos. Sci., 41, 2581-2594.

Huang, H.-C., and K. A. Emanuel, 1991: The effects of evaporation on frontal circulations. J. Atmos. Sci., 48, 619-628.

Jirak, I. L., and W. R. Cotton, 2006: Effect of air pollution on precipitation along the Front Range of the Rocky Mountains. J. Appl. Meteor. Climatol., 45, 236-245.

Khain, A. P., 2009: Notes on state-of-the-art investigations of aerosol effects on precipitation: A critical review. Environ. Res. Lett., 4, 015004, doi:10.1088/1748-9326/4/1/015004.

— D. Dosenfeld, and A. Pokrovsky, 2005: Aerosol impact on the dynamics and microphysics of convective clouds. Quart. J. Roy. Meteor. Soc., 131, 2639-2663.

Kuo, J. L., 1974: Further studies of the parameterization of the influence of cumulus convection on large-scale flow. J. Atmos. Sci., 31, 1232-1240.

Lawrence, B. A., M. I. Shebsovich, M. J. Glaudemans, and P. S. Tilles, 2003: Enhancing precipitation estimation capabilities at National Weather Service field offices using multi-sensor precipitation data mosaics. Preprints, 19th Conf. on IIPS, Long Beach, CA, Amer. Meteor. Soc., 15.1. [Available online at https://ams.confex.com/ams/annual2003/webprogram/ Paper54867.html.]

Lilly, D. K., 1962: On the numerical simulation of buoyant convection. Tellus, 14, 148-172.

Lynn, B., A. Khain, D. Rosefeld, and W. L. Woodley, 2007: Effects of aerosols on precipitation from orographic clouds. J. Geophys. Res., 112, D10225, doi:10.1029/2006JD007537.

Matsui, T., H. Masunaga, S. M. Kreidenweis, R. A. Pielke Sr., W.-K. Tao, M. Chin, and Y. J. Kaufman, 2006: Satellite-based assessment of marine low cloud variability associated with aerosol, atmospheric stability, and the diurnal cycle. J. Geophys. Res., 111, D17204, doi:10.1029/2005JD006097.

Meyers, M. P., R. L. Walko, J. Y. Harrington, and W. R. Cotton, 1997: New RAMS cloud microphysics parameterization. Part II: The two-moment scheme. Atmos. Res., 45, 3-39.

Molinari, J., 1985: A general form of Kuo's cumulus parameterization. Mon. Wea. Rev., 113, 1411-1416.
Molthan, A. L., and B. A. Colle, 2012: Comparisons of single- and double-moment microphysics schemes in the simulation of a synoptic-scale snowfall event. Mon. Wea. Rev., 140, 2982-3002.

Muhlbauer, A., T. Hashino, L. Xue, A. Teller, U. Lohmann, R. M. Rasmussen, I. Geresdi, and Z. Pan, 2010: Intercomparison of aerosol-cloud-precipitation interactions in stratiform orographic mixed-phase clouds. Atmos. Chem. Phys., 10, 81738196, doi:10.5194/acp-10-8173-2010.

Naud, C. M., D. J. Posselt, and S. C. van den Heever, 2012: Observational analysis of cloud and precipitation in midlatitude cyclones: Northern versus Southern Hemisphere warm fronts. J. Climate, 25, 5135-5151.

Pielke, R. A., Sr., and Coauthors, 1992: A comprehensive meteorological modeling system-RAMS. Meteor. Atmos. Phys., 49, 69-91.

Ramanathan, V., R. D. Cess, E. F. Harrison, P. Minnis, B. R. Barkstrom, E. Ahmand, and D. Hartmann, 1989: Cloudradiative forcing and climate: Results from the Earth Radiation Budget Experiment. Science, 243, 57-63.

Reeves, H. D., and G. M. Lackmann, 2004: An investigation of the influence of latent heat release on cold-frontal motion. Mon. Wea. Rev., 132, 2864-2881.

Rutledge, S. A., and P. V. Hobbs, 1983: The mesoscale and microscale structure and organizations of clouds and precipitation in midlatitude cyclones. VIII: A model for the "seederfeeder" process in warm-frontal rainbands. J. Atmos. Sci., 40, $1185-1206$.

Saleeby, S. M., and W. R. Cotton, 2004: A large-droplet mode and prognostic number concentration of cloud droplets in the Colorado State University Regional Atmospheric Modeling System (RAMS). Part I: Module descriptions and supercell test simulations. J. Appl. Meteor., 43, 182-195.

- and - 2008: A binned approach to cloud-droplet riming implemented in a bulk microphysics model. J. Appl. Meteor. Climatol., 47, 694-703.

$\longrightarrow,-$ D. Lowenthal, R. D. Borys, and M. A. Wetzel, 2009: Influence of cloud condensation nuclei on orographic snowfall. J. Appl. Meteor. Climatol., 48, 903-922.

— W. Werg, S. van den Heever, and T. L'Ecuyer, 2010: Impact of cloud-nucleating aerosols in cloud-resolving model simulations of warm-rain precipitation in the East China Sea. J. Atmos. Sci., 67, 3916-3930.

Schneider, T., K. L. Smith, P. A. O'Gorman, and C. C. Walker, 2006: A climatology of tropospheric zonal-mean water vapor fields and fluxes in isentropic coordinates. J. Climate, 19, 59185933.

Schultz, D. M., D. Keyser, and L. F. Bosart, 1998: The effect of large-scale flow on low-level frontal structure and evolution in midlatitude cyclones. Mon. Wea. Rev., 126, 1767-1791.

Seifert, A., C. Köhler, and K. D. Beheng, 2012: Aerosol-cloudprecipitation effects over Germany as simulated by a convectivescale numerical weather prediction model. Atmos. Chem. Phys., 12, 709-725, doi:10.5194/acp-12-709-2012.

Smagorinsky, J., 1963: General circulation experiments with the primitive equations. I. The basic experiment. Mon. Wea. Rev., 91, 99-164.

Stevens, B., and G. Feinfold, 2009: Untangling aerosol effects on clouds and precipitation in a buffered system. Nature, 461, 607-613, doi:10.1038/nature08281.

Stewart, R. E., K. K. Szeto, R. F. Reinking, S. A. Clough, and S. P. Ballard, 1998: Midlatitude cyclonic cloud systems and their features affecting large scales and climate. Rev. Geophys., 36, 245-273. 
Storer, R. L., S. C. van den Heever, and G. L. Stephens, 2010: Modeling aerosol impacts on convective storms in different environments. J. Atmos. Sci., 67, 3904-3915.

Szeto, K. K., and R. E. Stewart, 1997: Effects of melting on frontogenesis. J. Atmos. Sci., 54, 689-702.

Trenberth, K. E., and D. P. Stepaniak, 2003: Covariability of components of poleward atmospheric energy transports of seasonal and interannual timescales. J. Climate, 16, 36913705.

Twomey, S., 1977: The influence of pollution on the shortwave albedo of clouds. J. Atmos. Sci., 34, 1149-1152.

van den Heever, S. C., G. G. Carrió, W. R. Cotton, P. J. DeMott, and A. J. Prenni, 2006: Impacts of nucleating aerosol on Florida storms. Part I: Mesoscale simulations. J. Atmos. Sci. 63, $1752-1775$.

, G. L. Stephens, and N. B. Wood, 2011: Aerosol indirect effects on tropical convection characteristics under conditions of radiative-convective equilibrium. J. Atmos. Sci., 68, 699-718.
Walko, R. L., W. R. Cotton, M. P. Meyers, and J. Y. Harrington, 1995: New RAMS cloud microphysics parameterization. Part I: The single-moment scheme. Atmos. Res., 38, 29-62. Wang, J., S. C. van den Heever, and J. S. Reid, 2009: A conceptual model for the link between central American biomass burning aerosols and severe weather over the south central United States. Environ. Res. Lett., 4, 015003, doi:10.1088/1748-9326/4/ $1 / 015003$.

Xue, H., and G. Feingold, 2006: Large-eddy simulations of trade wind cumuli: Investigation of aerosol indirect effects. J. Atmos. Sci., 63, 1605-1622.

- A. Teller, R. Rasmussen, I. Geresdi, Z. Pan, and X. Liu, 2012: Effects of aerosol solubility and regeneration on mixed-phase orographic clouds and precipitation. J. Atmos. Sci., 69, 19942010.

Zubler, E. M., U. Lohmann, D. Lüthi, and C. Schär, 2011: Statistical analysis of aerosol effects on simulated mixed-phase clouds and precipitation in the Alps. J. Atmos. Sci., 68, 14741492. 